\title{
Retrospective Analysis of Pregnancy Terminations: 9-Years Experience at a Tertiary Hospital in Southeastern Turkey
}

\author{
Neslihan BAYRAMOGLU TEPE ${ }^{1}$, Reyhan GUNDUZ², Omer Faruk DIZIBUYUK ${ }^{3}$, Huseyin Caglayan OZCAN ${ }^{1}$ \\ Ozge KOMURCU KARUSERCI ${ }^{1}$, Seyhun SUCU ${ }^{1}$, Tanyeli GUNEYLIGIL KAZAZ ${ }^{4}$, Ali Irfan KUTLAR ${ }^{1}$
}

Gaziantep, Turkey

\section{ABSTRACT}

OBJECTIVE: To determine the indications for termination of pregnancy, and their consistency with autopsy data to offer an insight into termination of pregnancy having regard to conditions in Turkey.

STUDY DESIGN: Three hundred and ninety-one pregnancies terminated before the $24^{\text {th }}$ gestational week were enrolled in this study. Maternal age, gravidity, parity, abortion, the status of folic acid usage, consanguineous marital status, gestational week, anomalies that led to termination and pathological diagnoses were recorded. Anomalies that led to termination were grouped as central nervous system , cardiovascular system, gastrointestinal system, genitourinary system, pulmonary, musculoskeletal, head-neck, chromosomal, genetic, multiple anomalies and others. Four groups were formed based on the consistency of prenatal ultrasound diagnosis with pathological diagnosis.

RESULTS: Mean age, gravidity, parity, abortion, and gestational week were 28 years, 3, 1, 1, and 15.7 weeks, respectively. One hundred and thirty-eight $(35.2 \%)$ patients had consanguineous marriage. Three major causes of termination were central nervous system $(45.78 \%)$, head-neck $(17.4 \%)$ and multiple anomalies (14\%). One hundred and twenty-eight $(71.5 \%)$ patients with central nervous system anomalies were not using folic acid. Comparison of prenatal ultrasound findings with pathology results, $275(70.3 \%)$ patients had full consistency, $46(11.8 \%)$ had other findings at autopsy besides the confirmed sonographic findings, $34(8.7 \%)$ had some sonographic findings not confirmed at autopsy, and 4 (1\%) had no consistency between the findings.

CONCLUSION: Central nervous system anomalies constitute the most common indication for termination of pregnancy in this retrospective study. Low rate of periconceptional folic acid among those cases is remarkable. First-trimester screening for earlier detection of fetal anomalies may be important in highrisk groups such as those with consanguineous marriages.

Keywords: Fetal anomalies, Pregnancy, Termination

Gynecol Obstet Reprod Med 2021;27(1):34-39

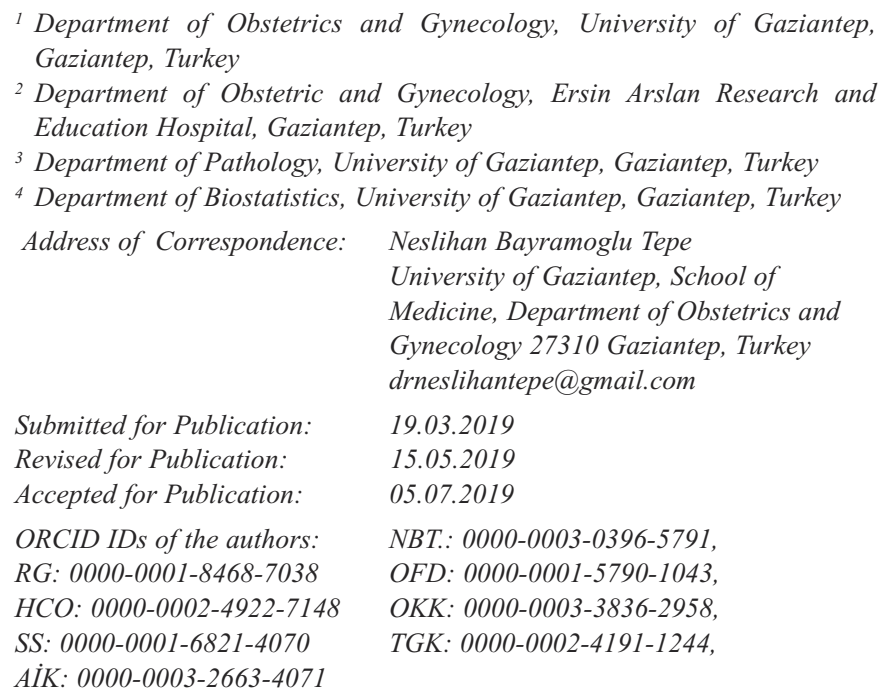

\begin{tabular}{c|c|}
\hline Quick Response Code: & Access this article online \\
\cline { 2 - 2 } & $\begin{array}{c}\text { Website: www.gorm.com.tr } \\
\text { e- mail: info@gorm.com.tr }\end{array}$ \\
\cline { 2 - 2 } & DOI:10.21613/GORM.2019.934 \\
\hline
\end{tabular}

\section{Introduction}

Detection rates of fetal anomalies have increased due to advances in imaging modalities and early diagnosis of congenital anomalies, which has led to an increased rate of pregnancy terminations (1). Detection rates of various congenital anomalies range between $44 \%$ and $86 \%$ depending on the type of anomaly (2-8).

Although second-trimester ultrasound (USG) screening between 18 and 23 weeks of gestation is routinely used as an anomaly scan, it is commonly accepted that most anomalies can be detected earlier (9).

Since 1983, it has been permitted by Turkish law to terminate a pregnancy at any gestational age if the pregnancy poses

How to cite this article: Bayramoglu Tepe N. Gunduz R. Dizibuyuk OF. Ozcan HC. Komurcu Karuserci O. Sucu S. Guneyligil Kazaz T. Kutlar AI. Retrospective Analysis of Pregnancy Terminations:9-Years Experience at a Tertiary Hospital in Southeastern Turkey. Gynecol Obstet Reprod Med 2021;27(1):34-39 
a danger to the mother's health and/or if there is a risk of severe fetal disorders that could cause disability or death (10). Gestational weeks, central nervous system (CNS) anomalies, the severity of the anomaly, and the presence of chromosomal abnormalities are the factors that affect the decision to terminate a pregnancy (11).

In this study, we aimed to show the distribution of indications for termination of pregnancy (TOP) over a period of eight years in our clinic and to emphasize the issues that need to be considered in TOP cases having regard to conditions in Turkey's by comparing the consistency of prenatal diagnoses with pathological diagnoses.

\section{Material and Method}

Three hundred and ninety-one pregnant women who presented to our clinic between January 2010-October 2018, who were not more than $24^{\text {th }}$ gestational week and who opted for termination were enrolled in our study. The patients included pregnant women who presented to our clinic for routine pregnancy follow-up and were found to have fetal anomalies in their fetus as well as pregnant women who were referred to our hospital from an external center, as our hospital is a tertiary center and were confirmed to have anomalies in their children at our hospital. The study was approved by the Clinical Trials Ethics Committee of Gaziantep University (2018/131). The study was carried out in accordance with the principles of the Declaration of Helsinki.

The obstetric and demographic data of the patients were recorded. The same experienced obstetrics team performed the ultrasonographic examinations by using Voluson E6R (GE Healthcare, Milwaukee, WI); transabdominal and transvaginal transducers with frequencies ranging between 2.14-6.10 MHz. Detected anomalies were grouped as CNS, cardiovascular system (CVS), gastrointestinal system (GIS), genitourinary system (GUS), pulmonary, musculoskeletal, head-neck, chromosomal, genetic, multiple anomalies and others (thorax, ocular, abdominal wall defects).

Gestational age was determined using the first-trimester crown-rump length measurement, and using the last menstrual date when said data was not available. Patients' age, gravidity, parity, abortion, consanguineous marriage, gestational week at the time of diagnosis, double and/or triple-quadruple test results, whether there were problems in previous pregnancies, as well as karyotype analysis results and pathological diagnoses, if any, were recorded.

After the diagnostic studies were completed, the couples were provided with counseling by a multidisciplinary healthcare team including gynecologists, neonatologists, pediatric surgeons to discuss the prognosis and treatment options, and termination was offered as an option. Consent was obtained from couples who agreed to an autopsy after termination. All fetal autopsies were performed by a single expert in perinatal pathology. The final diagnosis was made in each case on the basis of fetal autopsy findings. Ultrasound results were correlated with the findings of the autopsy carried out using the method described by Isaksen et al. except for one modification. Cases were divided into four groups according to the results of the correlations (12).

Group 1: Full agreement between USG and autopsy.

Group 2: Autopsy confirmed all USG findings but provided additional information about anomalies not diagnosed prenatally;

Group 3: Autopsy did not confirm all USG findings (some anomalies revealed at USG were not verified at autopsy);

Group 4: Total disagreement between USG and autopsy findings.

\section{Results}

The demographic and obstetric data of the patients enrolled in the study is summarized in table I. The consanguineous marriages rate was $40.4 \%$ (158/391).

In our study, the most common anomaly that led to TOP was CNS ( $n=179,45.8 \%)$ anomalies, whereas the least common anomalies were CVS and pulmonary system anomalies $(\mathrm{n}=2,0.5 \%)$ (Table II).

One hundred and twenty-eight (71.5\%) patients with detected CVS anomalies were not taking folic acid, whereas only $51(28.5 \%)$ patients were taking folic acid.

According to the comparison of prenatal USG findings with pathology results following the termination, $275(70.3 \%)$ patients were included in group 1, $46(11.8 \%)$ patients in group 2, $34(8.7 \%)$ patients in group 3 , and $4(1 \%)$ patients in group 4. Thirty-two $(8.2 \%)$ patients did not consent to pathological examination after termination.

Table I: Demographic and obstetric characteristics of the patients

\begin{tabular}{lccc}
\hline & Minimum & Maximum & Mean \pm Std. Deviation \\
\hline Age & 15 & 50 & $28.31 \pm 6.93$ \\
Gravidity & 1 & 10 & $3.05 \pm 1.94$ \\
Parity & 0 & 6 & $1.51 \pm 1.52$ \\
Abortion & 0 & 5 & $0.54 \pm 0.90$ \\
Gestational age at the time of diagnosis & 11 & 24 & $15.72 \pm 2.44$ \\
\hline
\end{tabular}


Table II: Distribution of anomalies according to the systems on ultrasonography findings

\begin{tabular}{|c|c|c|}
\hline Site of anomaly & $\mathbf{n}$ & $\%$ \\
\hline CNS & 179 & $45.78(179 / 391)$ \\
\hline NTD & 75 & $41.89(75 / 179)$ \\
\hline Anencephaly & 53 & $29.60(53 / 179)$ \\
\hline Holoprosencephaly & 43 & $24.02(43 / 179)$ \\
\hline Corpus callosum agenezis & 8 & $4.46(8 / 179)$ \\
\hline Head-neck & 68 & $17.39(68 / 391)$ \\
\hline Cystic hygroma & 51 & $75(51 / 68)$ \\
\hline Cleft palate-lip & 17 & $25(17 / 68)$ \\
\hline Multiple Anomalies & 55 & $14.07(55 / 391)$ \\
\hline GUS & 23 & $5.9(23 / 391)$ \\
\hline Polycystic kidney & 8 & $34.78(8 / 23)$ \\
\hline Bilateral renal agenesis & 6 & $26.08(6 / 23)$ \\
\hline Bilateral multicystic renal dysplasia & 5 & $21.73(5 / 23)$ \\
\hline PUV & 4 & $17.39(4 / 23)$ \\
\hline Other & 22 & $5.62(22 / 391)$ \\
\hline Congenital Anomaly & 16 & $4.09(16 / 391)$ \\
\hline Trizomi 21 & 12 & $75(12 / 16)$ \\
\hline Trizomi 18 & 3 & $18.75(3 / 16)$ \\
\hline $47, X X Y$ & 1 & $6.25(1 / 16)$ \\
\hline GIS & 13 & $3.32(13 / 391)$ \\
\hline Gastrochisis & 7 & $53.84(7 / 13)$ \\
\hline Omphalocele & 6 & $46.15(6 / 13)$ \\
\hline Musculoskeletal & 11 & $2.81(11 / 391)$ \\
\hline Skeletal dysplasia & 7 & $63.63(7 / 11)$ \\
\hline Osteogenesis imperfecta & 4 & $36.36(4 / 11)$ \\
\hline CVS & 2 & $0.51(2 / 391)$ \\
\hline Hypoplastic Left Heart & 1 & $50(1 / 2)$ \\
\hline Tetralogy of Fallot & 1 & $50(1 / 2)$ \\
\hline Pulmonary & 2 & $0.51(2 / 391)$ \\
\hline CCAM & 1 & $50(1 / 2)$ \\
\hline Diaphragmatic hernia & 1 & $50(1 / 2)$ \\
\hline
\end{tabular}

CNS: Central nervous system, NTD: Neural tube defect, GUS:Genitourinary system, PUV: Posterior urethral valve, Other: Other system anomalies (thorax, ocular, abdominal wall defects), GIS: Gastrointestinal system, CVS: Cardiovascular system, CCAM: Congenital cystic adenomatoid malformation

\section{Discussion}

Termination of pregnancy is a critical medical procedure due to its multidisciplinary nature $(13,14)$. In Turkey, it is legal to terminate an unwanted pregnancy with mutual spousal consent (or request of a single woman) until week 10 according to the Population Planning Law (15).

However, the inclusion of social media in popular medicine issues and the opportunistic approaches of politicians create some challenges in routine practice. In Turkey, TOP for maternal and fetal reasons is legal with the approval of an obstetrician and another physician who has contributed to the diagnosis in accordance with Law No 2827 (15) and TOP after the 24th gestational week is considered unethical according to the declaration of the Maternal-Fetal and Perinatology Association published in 2011 in Ankara (15). Therefore, babies with fetal anomalies should be diagnosed before 24 weeks of gestation and the option to terminate should also be offered within this period. Particularly, the first-trimester screening tests and ultrasonographic fetal evaluation between 18 and 22 weeks of gestation are vital for both potential maternal-fetal problems and for malpractice cases that constitute a significant cause of distress for obstetricians in Turkey.

In this study, we investigated the ultrasonographic distribution of the anomalies according to systems and the consistency of these anomalies with pathological diagnoses.

Anomalies of the CNS constituted nearly half of the indications for TOP (45.8\%, $\mathrm{n}=179)$. Of the CNS anomalies, neural tube defect (NTD) had the highest rate with $41.8 \%(n=75)$. This result is consistent with studies that show CNS malformations are the most common structural malformations that lead to TOP (16-19). On the other hand, considering the rate of folic acid use among termination cases due to CNS anomalies, only $28.5 \%(n=51)$ of the patients were taking folic acid. This rate is considerably low for Turkey, where healthcare services are easily accessible and folic acid can be directly obtained from primary health care institutions. In Turkey, patients refrain from using the recommended drugs within the early months of pregnancy as they think it may be harmful. Although the necessity of folic acid supplements is explained to patients, they have trouble starting or continuing to take the drug also due to the impact of the socio-cultural structure. We think that, in order to prevent this, patients should be provided with more detailed information especially in institutions providing primary health care services.

Kidney and urinary tract malformations constitute nearly $20-30 \%$ of the congenital anomalies detected before birth (20). The option to terminate a pregnancy for a urinary tract malformation should only be considered when renal functions are severely impaired and/or the presence of multiple anomalies supports the diagnosis of a syndrome or genetic condition (20). The rate of TOP due to GUS malformation ranges between $3 \%$ and $23 \%$ according to the literature (20). The rate of TOP due to GUS anomalies was $5.9 \%(n=23)$ in our series, which is consistent with the literature. In our study, the most common pathological diagnosis among GUS anomalies was polycystic kidney disease $(34.78 \%, n=8)$, followed by bilateral renal agenesis $(26.08 \%, \mathrm{n}=6)$, bilateral multi-cystic renal dysplasia $(21.73 \%, \mathrm{n}=5)$, and posterior urethral valve (PUV) $(17.39 \%, n=4)$. The option to terminate was offered since all GUS anomalies caused severe oligohydramnios or anhydramnios and the gestational week was not close to term.

According to a study by Vaknin et al., the most common cause of TOP was chromosomal abnormalities with $32 \%$, followed by CNS anomalies with $27 \%$, genetic syndromes with $5 \%$, and fetal infections with $8 \%$ in 22 cases (21). Amini et al. 
found the most common causes of TOP to be chromosomal abnormalities, CNS anomalies, and isolated congenital heart disease in $13.7 \%, 34.8 \%$ and $3.7 \%$ of their patients, respectively (22). We observed in our study that CNS anomalies constituted $45.8 \%$ of TOP causes, followed by head-neck anomalies with $17.4 \%$ and chromosomal abnormalities with $4.1 \%$. Multiple anomalies also constituted a significant group in our study with $14.1 \%$. It is possible to say that such a high prevalence of multiple anomalies is particularly due to the high rate of consanguineous marriages in our region $(35.2 \%, \mathrm{n}=138$ in our study). We consider that the significant differences between studies in terms of the prevalence of chromosomal abnormalities and genetic syndromes stem from the scope of the conducted etiological evaluation. Many families either do not consent to invasive procedures that would provide the actual diagnosis or to the TOP due to their religious beliefs even if chromosomal abnormalities have been detected.

In our study, the prevalence of fetuses with chromosomal abnormalities was $0.31 \%$, whereas the prevalence of fetuses with major and minor malformation without chromosomal abnormalities were $1.8 \%$ and $1.32 \%$, respectively (23). More than half of all congenital anomalies are diagnosed before birth in countries that have a routine USG screening policy (74\% of major and $46 \%$ of minor anomalies) (24). In our study, the rate of termination due to chromosomal abnormalities was $4.1 \%$ $(n=16)$. The most common chromosomal abnormality was trisomy 21 , which is consistent with other studies $(n=12,75 \%)$ (25). The prevalence of chromosomal abnormalities that lead to TOP has exhibited a dramatic increase from $5.7 \%$ to $12.7 \%$ within the last four years. This may stem from the increased number of women undergoing chromosomal screening tests in Turkey (24). Despite improvements in chromosomal abnormality screening and detection in Turkey, the overall rate of TOP due to chromosomal abnormalities $(4.1 \%)$ was lower in our study in comparison to previous studies (30-39\%) (25). The reason for such a low rate could be due to the small number of couples who consent to karyotype analysis or pregnancy termination due to regional and cultural factors in our region as compared to Western countries, the western part of our country and the part of Turkey that has a high socio-cultural level.

The rate of TOP due to isolated cardiac anomalies was determined at $0.5 \%(n=2)$ in our study. This rate was lower than the rate found in a study by Amini et al., i.e. 3.7\% (21). This could stem from the fact that many patients may neglect routine USG screening between gestational weeks 18 and 22, when the fetal heart can be best evaluated, together with the challenge of detecting cardiac anomalies in the first trimester.

Following TOP, confirming the prenatal diagnosis with a fetal autopsy is necessary to strengthen the trust between the physician and patient, and to provide thorough counseling services for the families. An autopsy can provide important information that changes the risk of recurrence, especially when the prenatal diagnosis is solely based on the results of USG screening (24). In our study, the majority of the families $(91.8 \%$, $359 / 391$ ) consented to an autopsy following termination. The reported rates vary between $30 \%$ and $100 \%$ according to the literature (12). In contrast to the study with low rates of autopsy $(14.6 \%)$ due to the lack of awareness of the necessity and benefits of autopsy in addition to the religious and cultural concerns of the Turkish population, we believe the fact that we had provided sufficient information for the families concerning the benefits and necessity of autopsy following termination resulted in a high rate of consent to autopsy in our series (25).

Kaasen et al. and Amini et al. found $65.8 \%$ and $62.8 \%$ consistency between prenatal USG findings and postmortem autopsy findings, respectively (20). A higher rate of consistency $(72.6 \%)$ was reported in another study that included 62 cases $(20)$. In our study, we found $70.3 \%(n=275)$ correlation between USG findings and pathological diagnosis (group 1). Moreover, the study mentioned above with $72.6 \%$ consistency rate was focused only on kidney and urinary tract anomalies, whereas we analyzed the rate of consistency not only for GUS but also for all other system anomalies. We still obtained a high rate of consistency between USG findings and pathological diagnosis. It is possible to assert the fact that a single experienced person, among the pathologists working at our hospital and who performed the fetal autopsy had an effect on the mentioned high rate of consistency. Three of 4 patients who did not match with USG findings were found to have chromosomal anomaly (trisomy 21), and one was a cardiac anomaly. (Group 4) Three patients with trisomy 21 had normal USG results, while autopsy showed duodenal atresia, atrioventricular septal defect, and polydactyly, respectively. The cardiac anomaly found as the hypoplastic left heart in USG was found to be tetralogy of Fallot on autopsy. Especially in the case of rarely observed anomalies, providing experience by referring to another perinatologist examination may lead to the discrepancy between USG and autopsy.

\section{Conclusion}

The decision to terminate a pregnancy involving anomalies can be affected by various factors such as the law and the healthcare system of a country as well as the socio-economic status, education level, religious, and cultural beliefs of couples (26). The importance of folic acid use should be emphasized in areas with low socio-economic status as in our region in order to reduce the prevalence of TOP due to CNS anomalies. Although there is still no universal guideline on TOP, action should be taken by considering the legal aspect as well as the differences both in beliefs and in socio-cultural levels in Turkey. Consent forms that clearly specify the information provided by the physician and the decision of couples should be signed for each pregnancy with detected anomalies. 
Acknowledgement: None.

Conflict of interest: There is no conflict of interest.

Funding: None.

Authors Contributions:NBT, RG, SS. Substantion contributions to the conception or design of the work, NBT, OFD, HCO, TGK: Analysis of interpretation of data, NBT, OKK: Drafting the work, NBT, AIK: Revising work critically for important intellectual content, NBT, AIK: Final approval of the version to be published.

\section{References}

1. Salvesen KA. Oyen L. Schmidt N. Malt UF. Eik-Nes SH. Comparison of long-term psychological responses of women after pregnancy termination due to fetal anomalies and after perinatal loss. Ultrasound Obstet Gynecol. 1997; 9(2):80-5. doi: 10.1046/j.1469-0705.1997.09020080.x.

2. Antonsson P. Sundberg A. Kublickas M. Pilo C. Ghazi S. Westgren M. et al. Correlation between ultrasound and autopsy findings after $2^{\text {nd }}$ trimester terminations of pregnancy. J Perinat Med. 2008;36(1):59-69. doi: 10.1515/ JPM.2008.005.

3. Boyd PA, Tondi F, Hicks NR, Chamberlain PF. Autopsy after termination of pregnancy for fetal anomaly: retrospective cohort study. BMJ. 2004;328(7432):137.

4. Chescheir NC, Reitnauer PJ. A comparative study of prenatal diagnosis and perinatal autopsy. J Ultrasound Med. 1994;13(6):451-6.

5. Isaksen CV. Eik-Nes SH. Blaas HG. Torp SH. Comparison of prenatal ultrasound and postmortem findings in fetuses and infants with central nervous system anomalies. Ultrasound Obstet Gynecol. 1998;11(4):24653. doi: 10.1046/j.1469-0705.1998.11040246.x.

6. Isaksen CV. Eik-Nes SH. Blaas HG. Tegnander E. Torp $\mathrm{SH}$. Comparison of prenatal ultrasound and postmortem findings in fetuses and infants with congenital heart defects. Ultrasound Obstet Gynecol. 1999;13(2):117-26. doi: 10.1046/j.1469-0705.1999.13020117.x.

7. Isaksen CV. Eik-Nes SH. Blaas HG. Torp SH. Fetuses and infants with congenital urinary system anomalies: correlation between prenatal ultrasound and postmortem findings. Ultrasound Obstet Gynecol. 2000;15(3):177-85. doi: 10.1046/j.1469-0705.2000.00065.x.

8. Isaksen CV. Eik-Nes SH. Blaas HG. Torp SH.van der Hagen CB. Ormerod E. A correlative study of prenatal ultrasound and post-mortem findings in fetuses and infants with an abnormal karyotype. Ultrasound Obstet Gynecol. 2000;16(1):37-45. doi:10.1046/j.1469-0705. 2000. 00157. x.

9. Pilu G. Nicolaides KH. Standard views for examination of the fetus. In Diagnosis of fetal abnormalities: The 18-23 Weeks Scan. In: Pilu G. Nicolaides KH. editors. London; England: CRC press; 1999. p. 3-4.

10. Aslan H. Yildirim G. Ongut C. Ceylan Y. Termination of pregnancy for fetal anomaly. Int J Gynaecol Obstet. 2007; 99(3):221-4. doi: 10.1016/j.ijgo.2007.05.047.

11. Bijma HH. van der Heide A. Wildschut HI. Decisionmaking after ultrasound diagnosis of fetal abnormalitiy. Reprod Health Matters. 2008;16(31 Suppl):82-9. doi: 10.1016/S0968-8080(08)31372-X.

12. Rodriguez MA. Prats P. Rodríguez I. Cusí V. Comas C. Concordance between prenatal ultrasound and autopsy findings in a tertiary center. Prenat Diagn. 2014;34 (8):784-9. doi: 10.1002/pd.4368.

13. Hamida EB. Ayadi I. Bezzine A. Rabii B. Hammouda SB. Bouguerra B. et al. Termination of pregnancy for fetal anomaly in a Tunisian population. S Afr J Obstet Gynaecol. 2017;23(2):69-70. doi:10.7196/SAJOG.2017. v23i2.1159.

14. Feldman N. Melcer Y. Hod E. Levinsohn-Tavor O. Svirsky R. Maymon R. Termination of pregnancy due to fetal abnormalities performed after 32 weeks' gestation: survey of 57 fetuses from a single medical center. J Matern Fetal Neonatal Med. 2018;31(6):740-6. doi: 10.1080/14767058.2017.1297406.

15. Ozyuncu O. Orgul G. Tanacan A. Aktoz F. Guleray N. Fadiloglu E. et al. Retrospective analysis of indications for termination of pregnancy. J Obstet Gynaecol. 2019;39 (3):355-8. doi: 10.1080/01443615.2018.1506427.

16. Statham H. Prenatal diagnosis of fetal abnormality: the decision to terminate the pregnancy and the psychological consequences. Fetal Matern Med Rev. 2002;13(4):213-47. doi:10.1053/beog.2000.0108.

17. Finlayson K, Downe S. Why do women not use antenatal services in low- and middle-income countries? A metasynthesis of qualitative studies. PLoS Med. 2013;10(1): e1001373.

18. Ben Natan M, Melitz O. Nurses' and nursing students' attitudes towards late abortions. Int Nurs Rev. 2011;58 (1): 68-73.

19. Breeze AC, Lees CC, Kumar A, Missfelder-Lobos HH, Murdoch EM. Palliative care for prenatally diagnosed lethal fetal abnormality. Arch Dis Child Fetal Neonatal Ed. 2007;92(1):F56-8. doi: 10.1136/adc.2005.092122.

20. Simoens E. Hindryckx A. Moerman P. Claus F. Catte LD. Termination of pregnancy for renal malformations. Pediatr Nephrol. 2015;30(9):1443-9. doi:10.1007/s00 467-015-3085-7.

21. Vaknin Z. Ben-Ami I. Reish O. Herman A. Maymon R. Fetal abnormalities leading to termination of singleton pregnancy: the 7-year experience of a single medical center. Prenat Diagn. 2006;26(10):938-43. doi: 10.1002/ pd.1531.

22. Amini H. Antonsson P. Papadogiannakis N. Ericson K. Pilo C. Eriksson L. et al. Comparison of ultrasound and autopsy findings in pregnancies terminated due to fetal anomalies. Acta Obstet Gynecol Scand. 2006;85(10): 
1208-16. doi: 10.1080/00016340600880886.

23. Romosan G. Henriksson E. Rylander A. Velentin L. Diagnostic performance of routine ultrasound screening for fetal abnormalities in an unselected Swedish population in 2000-2005. Ultrasound Obstet Gynecol. 2009;34 (5):526-33. doi: 10.1002/uog.6446.

24. Grandjean H. Larroque D. Levi S. Sensitivity of routine ultrasound screening of pregnancies in the Eurofetus Team. Ann N Y Acad Sci. 1998;847:118-24. doi: 10.1111/j.1749-6632.1998.tb08932.x.

25. Corbacıoğlu A. Aslan H. Aydın S. Akbayır O. Ersan F. Alpay V. et al. Trends in fetal indications for termination of pregnancy between 2002 and 2010 at a tertiary referral centre. J Turk Ger Gynecol Assoc. 2012;13(2):85-90. doi:10.5152/jtgga.2012.09. eCollection 2012.

26. Al-Alaiyan S. An Islamic legal perspective on the status of the malformed fetus. J Palliat Care Med. 2014;4:172. doi:10.4172/2165-7386.1000174. 